\title{
Assessment of anthropogenic load and ecosystem stability in the land cadastre zoning of megacities
}

\author{
Stanislav Dubrova ${ }^{1 *}$, Pavel Zelenkovskiy ${ }^{2}$, Sergey Lebedev², Ivan Podlipskiy ${ }^{1}$, \\ and Elena Chernova ${ }^{2}$ \\ ${ }^{1}$ Russian State Pedagogical University named after Herzen, nab. Moika Rivers 48, Building 5, \\ 191186, St. Petersburg, Russia \\ ${ }^{2}$ Institute of Earth Sciences, St. Petersburg State University, Universitetskaya Embankment 7-9, \\ 199034, St. Petersburg, Russia
}

\begin{abstract}
With the increasing number of megacities, the constant expansion of their borders, and the often chaotic, unreasonable land-use planning, even those sites with potential recreational use suffer from enormous anthropogenic pressure. Defining the limits of ecosystem stability is one of the most important scientific research, which allows setting permissible anthropogenic impact in the land cadastre zoning of megacities. This investigation presents the integral assessment of net anthropogenic load on the environment and boundaries of the natural soil geochemical background change.
\end{abstract}

\section{Introduction}

One of the most important large urban agglomerations ecological problems is the subsurface geological environmental pollution from man-made activity. The movement of substance flow migration of anthropogenically-modified load and geological bodies is similar and is governed by the same laws. The geochemical impact is typical for almost all types of technogenesis. It is widely spread and takes place during the whole period of change using the territory and is reflected in all components of the natural complex. Understanding the processes inside the body is of basic universal nature. Careful consideration of the presented approach and methodology upon the example of similar objects is extremely relevant and it can prevent environmental disasters both in the urban environment and in the mineral resource industry in the future.

The major problem is the difference, sometimes significant, in background concentrations of elements, e.g. changes of the geochemical background within the ecosystem stability under the influence of anthropogenic load. A clear integral assessment of all components of registered geochemical concentrations in objects being monitored is required to understand the processes inside anthropogenically-modified bodies and it will allow for more relevant decisions taken during their reclamation [1].

\footnotetext{
${ }^{*}$ Corresponding author: dubrova.stanislav@gmail.com
} 


\section{Materials and methods}

To demonstrate the integral assessment of the migration flow of substances in the geological environment a huge coastal marine historical landfill, "Novoselki" and "Severnyi" water treatment plant slug beds, St. Petersburg, Russia, was taken as an example of a geological anthropogenic body (solid waste landfill). Hereafter in the article, these two facilitates are combined in a single anthropogenically-modified body and are considered as a solid domestic waste landfill and adjacent airfield. The total area of these territories is 443 ha. The distance to the Gulf of Finland is $10 \mathrm{~km}$ with terrain absolute elevation decrease from $25 \mathrm{~m}$ to $4 \mathrm{~m}$ above the sea level in the direction of the sea. The monitoring of the landfill and adjacent territory was carried out in 2011, 2013 and 2014 by the Russian Geoecological Center (RGEC) and the SPBU Ecological Geology Department. The NovoOrlovskiy Park is located $3.5 \mathrm{~km}$ south-east of the landfill, and the authors consider it as a recreation urban functional area from a geochemical point of view [1]. Currently a research and technology complex is being built on this territory. In 2009 the "Osobiye Economicheskiye Zony" company monitored soils and lands within the whole construction area of 120 ha. The authors participated in the analysis of analytical materials obtained.

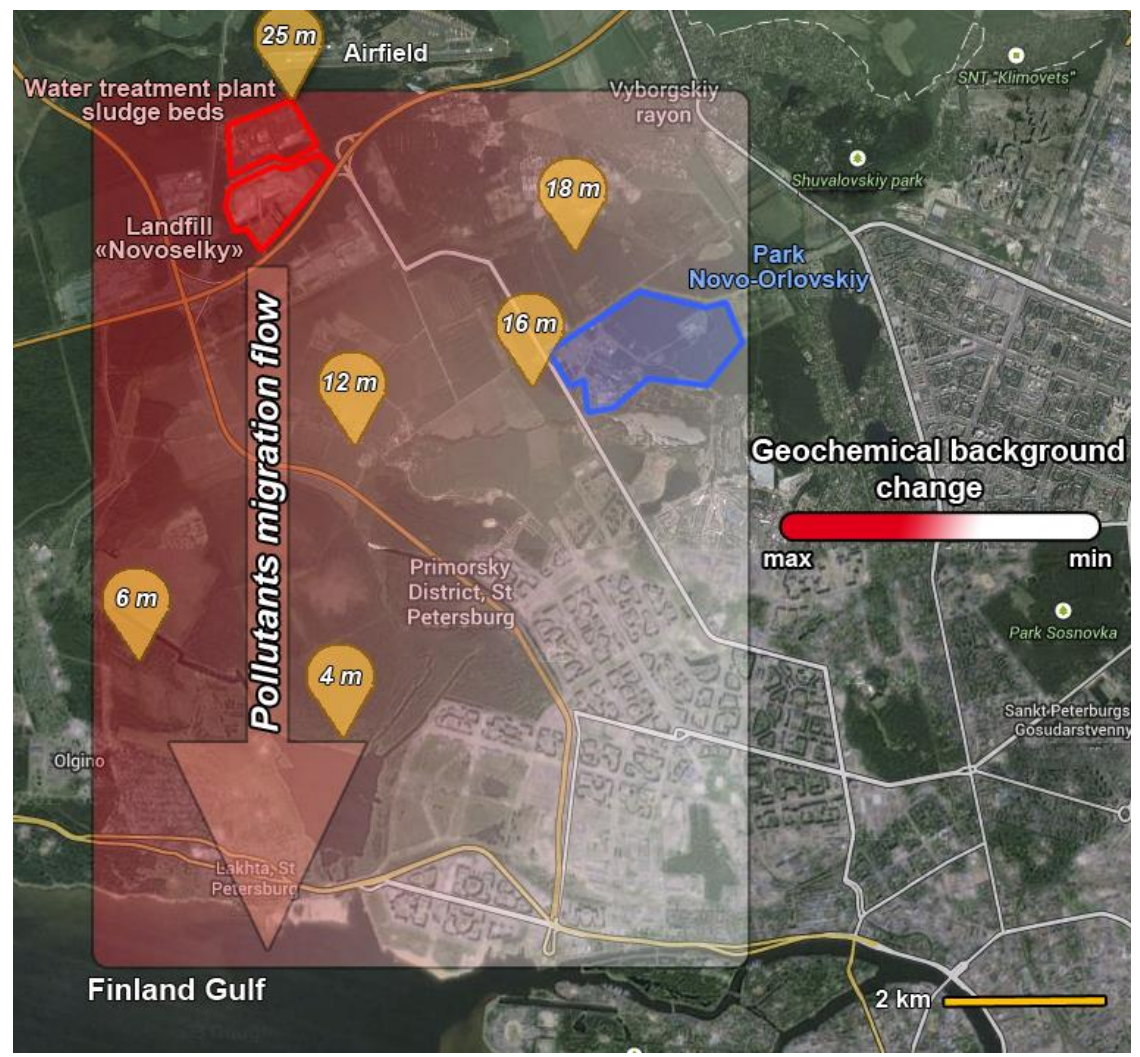

Fig. 1. The scheme of the study objects location with altitude marks.

This article considers geochemical data of soil and land samples taken from 0-0.2 m. Sub-soils are represented by fine-grained and very fine-grained sand. The landfill area and park territory grids sampling included 110 points each. The total volume is 220 points. The analysis was performed for 10 heavy metals $(\mathrm{Hg}, \mathrm{Pb}, \mathrm{Cd}, \mathrm{As}, \mathrm{Zn}, \mathrm{Ni}, \mathrm{Cr}, \mathrm{Co}, \mathrm{Cu}, \mathrm{Mn})$ and organic compounds (benzo(a)pyrene, petroleum products). The pollutants concentration 
was determined in the accredited laboratories of St. Petersburg and in the SPBU Ecological Geology Department by the flame atomic absorption spectrometer Shimadzu 280FS AA.

\section{Results and discussion}

First of all, geochemical samplings were subject to descriptive statistics methods [2]. Average values were calculated (arithmetical mean for elements with distribution close to normal; geometric mean for elements with log-normal distribution) for construction of each element, as well mean deviation was calculated. Then abnormality boundaries were determined (under the "three sigma rule") that define errors and emissions (both positive and negative) that allow assessing basic statistical principles for each sampling. Concentrations beyond the allowable limits were replaced by values that represent a half of hardware detection. Henceforth, repeated descriptive statistics (Table 1) of normalized samplings was performed. Table 1 gives the results of calculations: mean values for each assessed pollutants, mean geometric value, minimal and maximum values, lower (25\%) and upper $(75 \%)$ quartile values, standard deviations. Figure 1 graphically shows changes in the level of geochemical background with points that are associated with data from Table 1. This is a graphic representation of changes in the natural ecosystem stability.

For the integral obtaining of net anthropogenic load and changes of the geochemical background in the area where the landfill body impacts the environment, the park's sampling was deducted from the landfill's normalized sampling. Thus, the difference of interval values is the reflection of contamination resulting from the landfill body. Table 1 reflects final values.

Table 1. Integral assessment of the net anthropogenic load and the geochemical background changes

\begin{tabular}{|c|c|c|c|c|c|c|}
\hline \multicolumn{7}{|c|}{ Landfill } \\
\hline & Mean & Minimum & Maximum & $\begin{array}{l}\text { Lower } \\
\text { Quartile }\end{array}$ & $\begin{array}{l}\text { Upper } \\
\text { Quartile }\end{array}$ & Std.Dev. \\
\hline $\mathrm{Hg}$ & 0,29 & 0,01 & 4,20 & 0,06 & 0,15 & 0,55 \\
\hline $\mathrm{Pb}$ & 94,30 & 20,00 & 657,00 & 27,00 & 50,00 & 154,60 \\
\hline As & 6,26 & 0,70 & 28,00 & 3,00 & 6,30 & 5,44 \\
\hline $\mathrm{Cd}$ & 2,22 & 0,03 & 23,80 & 0,07 & 1,48 & 4,81 \\
\hline $\mathrm{Zn}$ & 169,43 & 7,80 & 1000,00 & 30,00 & 106,00 & 265,07 \\
\hline $\mathrm{Ni}$ & 26,79 & 2,50 & 150,00 & 17,70 & 30,00 & 21,19 \\
\hline Co & 10,48 & 2,08 & 50,00 & 5,00 & 10,00 & 10,03 \\
\hline $\mathrm{Cr}$ & 81,70 & 5,00 & 2000,00 & 20,00 & 47,62 & 212,24 \\
\hline $\mathrm{Cu}$ & 75,16 & 8,33 & 700,00 & 10,00 & 38,10 & 146,03 \\
\hline $\mathrm{Mn}$ & 488,41 & 70,00 & 3000,00 & 166,67 & 500,00 & 642,53 \\
\hline Benz & 0,01 & 0,00 & 0,14 & 0,00 & 0,01 & 0,02 \\
\hline Petrol & 160,62 & 7,00 & 1880,00 & 15,00 & 88,00 & 373,37 \\
\hline \multicolumn{7}{|c|}{ Special economic zone Novo-Orlovskaya } \\
\hline & Mean & Minimum & Maximum & $\begin{array}{c}\text { Lower } \\
\text { Quartile }\end{array}$ & $\begin{array}{l}\text { Upper } \\
\text { Quartile }\end{array}$ & Std.Dev. \\
\hline $\mathrm{Hg}$ & 0,03 & 0,01 & 0,16 & 0,01 & 0,04 & 0,04 \\
\hline $\mathrm{Pb}$ & 8,12 & 0,18 & 23,60 & 2,90 & 12,60 & 6,08 \\
\hline As & 0,36 & 0,01 & 1,50 & 0,01 & 0,47 & 0,47 \\
\hline $\mathrm{Cd}$ & 0,06 & 0,01 & 0,25 & 0,01 & 0,11 & 0,07 \\
\hline $\mathrm{Zn}$ & 19,20 & 0,01 & 44,90 & 11,55 & 24,20 & 9,44 \\
\hline $\mathrm{Ni}$ & 0,73 & 0,01 & 2,90 & 0,09 & 1,30 & 0,75 \\
\hline Co & 0,60 & 0,01 & 2,80 & 0,04 & 0,97 & 0,70 \\
\hline $\mathrm{Cr}$ & 0,37 & 0,01 & 2,30 & 0,01 & 0,45 & 0,59 \\
\hline $\mathrm{Cu}$ & 13,87 & 0,88 & 32,10 & 10,00 & 17,85 & 6,72 \\
\hline Mn & 135,88 & 12,90 & 275,34 & 100,00 & 172,95 & 52,74 \\
\hline Benz & 0,00 & 0,00 & 0,01 & 0,00 & 0,00 & 0,00 \\
\hline Petrol & 8,64 & 1,00 & 23,50 & 1,00 & 12,90 & 6,89 \\
\hline \multicolumn{7}{|c|}{ Net antropogenic load } \\
\hline & Mean & Minimum & Maximum & $\begin{array}{c}\text { Lower } \\
\text { Quartile }\end{array}$ & $\begin{array}{c}\text { Upper } \\
\text { Quartile }\end{array}$ & Std.Dev. \\
\hline $\mathrm{Hg}$ & 0,26 & 0,01 & 4,04 & 0,06 & 0,11 & 0,51 \\
\hline $\mathrm{Pb}$ & 86,18 & 19,82 & 633,40 & 24,10 & 37,40 & 148,51 \\
\hline As & 5,90 & 0,70 & 26,50 & 2,99 & 5,84 & 4,98 \\
\hline $\mathrm{Cd}$ & 2,15 & 0,03 & 23,55 & 0,07 & 1,37 & 4,75 \\
\hline $\mathrm{Zn}$ & 150,23 & 7,79 & 955,10 & 18,45 & 81,80 & 255,64 \\
\hline $\mathrm{Ni}$ & 26,06 & 2,50 & 147,10 & 17,61 & 28,70 & 20,44 \\
\hline Co & 9,88 & 2,08 & 47,20 & 4,96 & 9,04 & 9,33 \\
\hline $\mathrm{Cr}$ & 81,33 & 5,00 & 1997,70 & 20,00 & 47,17 & 211,65 \\
\hline $\mathrm{Cu}$ & 61,29 & 7,45 & 667,90 & 0,00 & 20,25 & 139,30 \\
\hline $\mathrm{Mn}$ & 352,52 & 57,10 & 2724,66 & 66,67 & 327,05 & 589,79 \\
\hline Benz & 0,01 & 0,00 & 0,14 & 0,00 & 0,01 & 0,02 \\
\hline Petrol & 151,98 & 6,00 & 1856,50 & 14,00 & 75,10 & 366,48 \\
\hline
\end{tabular}

In this case, it is very important that the geochemical database of the Novo-Orlovskiy city forest area includes possible atmospheric contamination from adjacent industrial 
facilities and the air strip. Thus, the results obtained allow dividing the regional anthropogenic load and identify negative environmental impact from the landfill. Figure 1 gives a zoning scheme for substance migration flows. This model is universal since geochemical zoning of concentrations can be made in all anthropogenic objects and geological bodies. The frames of application for this model can vary from a local object to a city or a region [5].

It is important to note that the background is not a regional characteristic in this case, but it refers to the geological object localization area, which is a landfill body in our case. The ecosystem stabilization process is expressed in background level changes in the area of increased anthropogenic load. In this region it decreases to values that show its almost complete absence.

Figure 2 gives a scheme with marks of integral values of pollutant concentrations. The whole impact area of the object is divided by three parts; the high anthropogenic impact area, the intermediate and the recreational/background [2]. This zoning approach is universal and it can be applied to investigations of any geological objects. Intrinsically it represents modeling which is a potentially effective tool for controlling substance migration flow and, as a consequence, the whole contamination.

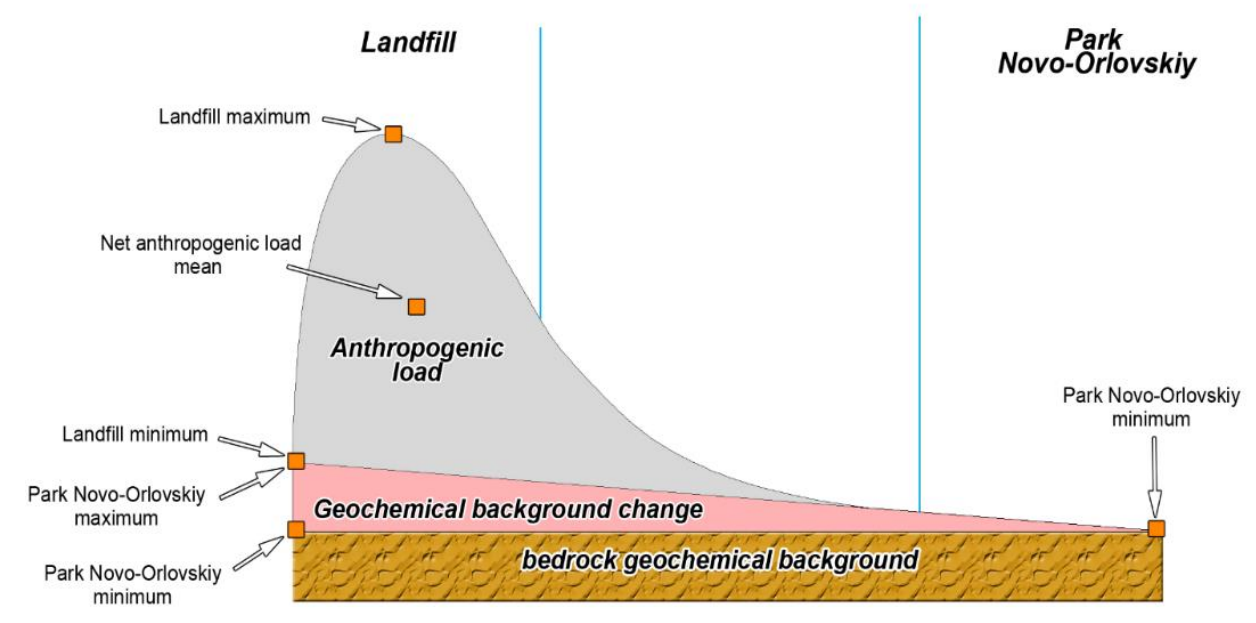

Fig. 2. Integral assessment of the net anthropogenic load and the geochemical background changes.

The lower boundary of the net anthropogenic load can be minimal values of concentrations of landfill elements that are identical to maximum registered values of the park zone. This proves the appropriateness of the whole methodology and the discussion logics. In return, minimal concentration values of park elements include background values associated with the content of bottom rocks.

The values of the upper boundary of the geochemical background changes are, thus, the ecosystem stability limit [1,3]. When increasing the anthropogenic load above this boundary of the system, it can't withstand external impact factors anymore and passes into the degradation stage.

Contamination from landfill masses can be assessed and identified based upon the results obtained. The MPC values of pollutant concentrations in landfill masses with no respect to background values (regional and changed) are: $\mathrm{Hg}-0.12 \mathrm{MPC}, \mathrm{Pb}-2.7 \mathrm{MPC}$, As - 3 MPC, Cd - 4.3 MPC, Zn - 2.5 MPC, Ni - 6.5 MPC, Co - 1.98 MPC, Cr - 13.5 MPC, $\mathrm{Cu}-20.5$ MPC, Mn - 6 MPC, benzo(a)perene - 0.5 MPC. Thus, relevant exceeding 
of concentrations in soils of the research area has been registered for all analyzed elements and compounds. Their supply can only be addressed to landfill masses.

The important point is that contamination with benzo(a)pyrene and petroleum products is exclusively related to landfill masses and is localized in the landfill body. Regional and anthropogenic-load-modified concentrations of organic pollutants do not exceed the MPC and tend toward zero. Contamination with organic compounds from adjacent industrial objects (automobile plant and airfield) and their migration through the atmosphere can be regarded as insignificant.

The amount of the geochemical background change under the influence of anthropogenic load for each element is as follows: $\mathrm{Hg}-0.03 \mathrm{MPC}, \mathrm{Pb}-0.37 \mathrm{MPC}$, As 0.37 MPC, Cd - 0.24 MPC, Zn - 0.37 MPC, Ni - 0.36 MPC, Co - 0.28 MPC, Cr - 0.19 MPC, $\mathrm{Cu}-5.05 \mathrm{MPC}, \mathrm{Mn}-2.07 \mathrm{MPC}$, benzo(a)perene - 0.25 MPC. Change of the local geochemical background is not correlated to the amount of pollutants concentration in landfill masses. To a greater extent it depends on pollutant peculiarities in landfill masses and its potential for self-restoration. The amount of the background concentrations change is rather large. As a parameter that describes the natural ecosystem potential for selfrestoration, it significantly influences the results of monitoring geochemical investigations in general. In case of integral division of elements and compounds concentrations registered in samples, the value of numerical data is substantially increased.

\section{Conclusion}

In the conclusions of investigations the actual data proved significant change of the geochemical background in areas that undergo various anthropogenic impacts. Assessment of precise geometric frames (limit) of contamination substantially increases the interpretation quality and is a significant factor when modeling hydrogeological conditions and creating a thermodynamic model of the geological object.

The approach presented in the article can be used to assess the substance migration upon a soil profile, including consideration of geochemical data from deeper horizons. In this case, the integral assessment of pollutants concentrations will be indirectly described by their migration under the influence of underground waters. When we consider geological features of the object under research such division becomes very important. It allows for a different approach to the assessment of dangerous anthropogenically-modified objects in the near-shore zone, such as a solid domestic waste landfill, for which underground drainage is the basic risk criteria [3,4].

Geochemical background change is clearly visible when comparing matrices of geochemical objects in zones with various anthropogenic loads within the research area. When modeling processes inside geological bodies, a large number of parameters and properties are used. Thus, notable accuracy of input data is required. It's extremely important to consider changes of the geochemical background and integrally determine the anthropogenic load. Investigation of the ecosystem self-restoration potential will promote more precise determination of the boundaries of environmental negative impact.

\section{References}

1. S.V. Dubrova, I.I. Podlipskiy, V.V. Kurilenko, W. Siabato, Environ Pollut, 197 165$172(2015)$

2. S.V. Dubrova, V. German, IOP Conf. Ser.: Mater. Sci. Eng., 663, 1-5 (2019)

3. A. Marzougui, A.Mammou, C R Geosci, 338(16), 1176-1183 (2006) 
4. I.I. Podlipskiy, Ecological and geological assessment of the territory of landfills for household waste (LAP Lambert Academic Publishing, 2015)

5. M. Vorenhout, N.M. van Straalen, H.J.P. Eijsackers, Environ Toxicol Chem, 19, 21612163 (2000) 